\title{
Memprediksi Pola Ban Hero Pada Game Mobile Legends Menggunakan Algoritma Apriori
}

\author{
Jordy Lasmana Putra ${ }^{1}$, Syarah Seimahuira ${ }^{2}$ \\ ${ }^{1,2}$ Program Studi Teknik Informatika, Fakultas Teknologi Informasi, Universitas Nusa Mandiri \\ J1. Raya Jatiwaringin, Cipinang Melayu, Makasar, Jakarta Timur-13630, Indonesia \\ e-mail: ${ }^{1}$ jordy.jlp@ @usamandiri.ac.id, ${ }^{2}$ syarah.yrs@ nusamandiri.ac.id
}

Artikel Info : Diterima : 01-07-2021 | Direvisi : 12-07-0000| Disetujui : 21-07-2021

\begin{abstract}
Abstrak - Di era digital seperti sekarang ini perkembangan video game begitu pesat, dari mulai yang berbasis console sampai ke perangkat smartphone. Salah satu genre video game yang sedang trend adalaha Multiplayer Online Battle Arena (MOBA) dengan salah satu game MOBA yang digandrungi yaitu game Mobile Legends. Dalam memenangkan sebuah pertandingan di dalam game mobile legend, diperlukan strategy permainan yang baik dari masing-masing tim untuk mempertahankan base dan menghancurkan base lawan, salah satunya adalah dengan melakukan Ban Hero atau melarang beberapa hero yang ada agar tidak bisa digunakan baik untuk tim lawan maupun tim sendiri. Oleh karena itu penelitian ini dilakukan untuk memprediksi pola ban hero dengan menggunakan algoritma Apriori, yang dilakukan pada 9 atribut Hero Mobile Legend. Dari hasil yang dilakukan diketahui bahwa Hero CHOU lebih banyak digunakan dan tidak di ban dibandingkan 8 Hero lainnya.
\end{abstract}

Kata Kunci : Mobile Legends, Data Mining, Algoritma Apriori

\begin{abstract}
In this digital era, the development of video games is so rapid, from console-based to smartphone devices. One of the trending video game genres is the Multiplayer Online Battle Arena (MOBA) with one of the most popular MOBA games, the Mobile Legends game. In winning a match in a Mobile Legends game, a good game strategy is needed from each team to defend the base and destroy the opponent's base, one of which is by Ban Hero or banning some existing heroes so that they cannot be used both for the opposing team and for the opposing team. own team. Therefore, this study was conducted to predict the pattern of hero tires using the Apriori algorithm which was carried out on 9 attributes of Hero Mobile Legends. From the results it is known that CHOU Hero is more widely used and not banned compared to 8 other Heroes
\end{abstract}

Keywords : Mobile Legends, Data Mining, Apriori Algorithm

\section{PENDAHULUAN}

Video game adalah permainan yang sangat digandrungi oleh manusia, dari usia anak-anak bahkan sampai usia dewasa bermain video game. Video game merupakan industri yang paling menonjol (Funk, 1993) dalam (Pascarella et al., 2018) Di era digital seperti sekarang ini perkembangan video game begitu pesat, dari mulai yang berbasis console sampai ke perangkat-perangkat smartphone. Salah satu genre video game yang sedang trend adalaha Multiplayer Online Battle Arena (MOBA) (Damariva et al., 2018) salah satu game MOBA yang digandrungi salah satunya adalah game Mobile Legends. Mobile Legends merupakan permainan game mobile yang merupakan game strategy dimana ada 2 buah tim yang bertanding dalam sebuah arena, dimana masingmasing tim bertugas untuk menjaga tower-tower atau di sebut base agar tidah di hancurkan oleh tim lawan, dan untuk memenangkan permainan adalah berhasil menghancur kan base-base musuh.

Video game bagi sebagian orang di anggap memiliki pengaruh negatif, akan tetapi dibalik itu semua ada beberapa video game yang sudah diakui bahkan dimasukan kedalam kejuaraan sekelas SEA Games, salah satunya game Mobile Legend ini. Dalam memenangkan sebuah pertandingan di dalam game mobile legend, diperlukan strategy permainan yang baik dari masing-masing tim untuk mempertahankan base dan menghancurkan base lawan, salah satunya adalah dengan melakukan Ban Hero atau melarang beberapa hero yang ada agar tidak bisa digunakan baik untuk tim lawan maupun tim sendiri.

Penelitian terdahulu telah dilakukan oleh (Summerville et al., 2016) yang berjudul Draft-analysis of the Ancients: predicting draft picks in DotA 2 using machine learning yang melakukan prediksi pemilihan hero pada 
game Dota 2, penelitian selanjutnya yang dilakukan oleh (Mustofa et al., 2018) yang berjudul Implementasi Algoritma Apriori Untuk Analisa Pemilihan Tipe Karakter Pada Permainan Mobile Legend yang menganalisa pola pemilihan karakter pada game Mobile Legend dan penelitian yang dilakukan oleh (Leonardo et al., 2018) yang berjudul Sistem Rekomendasi Item Pada Game Dota 2 dengan Multilayer Perceptron Neural Network melakukan prediksi rekomendasi item pada game Dota 2. Dalam penelitian ini penulis melakukan prediksi pola ban hero pada game mobile legends.

Dari kuisioner yang sudah di sebar oleh peneliti, terdapat 150 tanggapan dari responden, dari 150 tanggapan $88,7 \%$ adalah player game mobile legend dan $11,3 \%$ bukan player mobile legend, dari $88,7 \%$ player tersebut menyatakan bahwa ban hero sangat berpengaruh untuk kemenangan sebuah tim. Oleh karena itu penelitian ini dilakukan guna memprediksi pola ban hero dengan menerapkan data mining. Data mining merupakan proses dalam menganalisa data untuk dapat menemukan pola dari kumpulan data yang ada, kemudian dianalisa dan diolah menjadi sebuah informasi yang digunakan dalam menentukan pola dalam membuat keputusan (Putra et al., 2019). Proses data mining kerap kali dikenal dengan istilah Knowledge Discovery in Database (KDD) dan untuk menerangkan proses penggalian informasi tersembunyi dari suatu basis data yang besar yang digunakan secara bergantian (Syahputri, 2020). Terdapat beberapa jenis algoritma pada data mining yang dapat digunakan untuk memprediksikan hasil dari pengolahan data. Salah satunya adalah algoritma apriori yang berpengaruh guna melakukan mining frequent Itemset dalam membentuk suatu aturan asosiasi (Gunadi \& Sensuse, 2016). Algoritma apriori ini akan sesuai apabila digunakan apabila memiliki hubungan antar item yang akan dianalisis. Kumpulan data tersebut memiliki banyak informasi yang sangat bermanfaat untuk dapat dimanfaatkan, salah satunya untuk mencari tahu pola suatu kondisi (Fachrurozi et al., 2020) Sehingga tepat digunakan dalam penelitian memprediksi pola ban hero pada game Mobile Legends menggunakan algoritma Apriori.

\section{LANDASAN TEORI}

Pada penerapannya aturan yang menyatakan asosiasi diantara beberapa atribut disebut dengan affinity analysis atau market basket analysis (Putra et al., 2019). Analisis asosiasi ataupun dalam sebutan inggris diketahui dengan association rule mining ialah metode data mining untuk menciptakan pola ketentuan sesuatu gabungan item. Salah satu tahap analisis asosiasi yang menarik atensi banyak pengamat untuk menciptakan algoritma yang efektif menggambarkan analisis pola frekuensi besar (frequent pattern mining).

Analisis asosiasi ini sering kali digunakan untuk menganalisa data buat keperluan membuat strategi pemasaran, desain katalog, dan proses pembuatan keputusan bisnis. Secara tradisional, ketentuan asosiasi digunakan untuk menciptakan trend bisnis dengan mengamati pola transaksi konsumen, Algoritma apriori merupakan algoritma sangat populer untuk menciptakan pola frekuensi teratas. Pola frekuensi besar merupakan pola item di dalam sesuatu database yang mempunyai frekuensi ataupun support di atas ambang batasan tertentu sehingga disebut dengan sebutan minimum support.

Algoritma apriori dibagi menjadi beberapa tahap yang disebut iterasi atau pass yaitu:

1. Pembentukan kandidat itemset, dari iterasi sebelumnya diperoleh kandidat k-itemset yang kemudian dibentuk dari kombinasi (k-1) itemset. Pemangkasan kandidat k-itemset yang subset-nya yang berisi k1 item tidak termasuk dalam pola frekuensi tinggi dengan panjang k-1merupakan salah satu cara dari algoritma Apriori.

2. Penghitungan support dari setiap kandidat k-itemset. Support dari setiap kandidat k-itemset didapat dengan menscan database untuk melakukan akumulasi dariu jumlah transaksi yang memuat semua item di dalam kandidat k-itemset tersebut. Ciri algoritma Apriori disini perlunya penghitungan dengan scan pada keseluruhan database sebanyak k-itemset terpanjang.

3. Memastikan pola dari frekuensi bernilai tinggi karena pola dengan frekuensi tinggi tersebut yang memuat k-itemset ditentukan dari calon k-itemset yang nilai supportnya lebih besar dari minimum support.

Bernilai tidaknya sesuatu asosiasi bisa dikenal dengan 2 tolak ukur, ialah: support serta confidence. Confidence ataupun nilai kepastian merupakan kuatnya hubungan antar- item dalam aturan asosiasi sebaliknya Support ataupun nilai penunjang merupakan persentase gabungan item tersebut dalam database. Jarak dari nilai antara $0 \%-100 \%$ diterapkan pada pencarian pola kaidah asosiasi mengunakan dua buah parameter nilai tersebut (GIBRAN, 2016). Metodologi dasar analisis asosiasi terbagi menjadi dua tahap yaitu: analisa pola frekuensi tinggi Pada tahapan ini dicari kombinasi item yang dapat memenuhi syarat minimum dari nilai support dalam suatu database. Nilai support dari sebuah item didapatkan dengan rumus berikut:

$$
=\frac{\sum \text { pemilihan mengandung } A}{\Sigma \text { Transaksi }} * 100 \%
$$

Setelah pola frekuensi tinggi ditemukan maka selanjutnya terdapat proses pembentukan aturan assosiatif, kemudian dilakukan pencarian aturan assosiatif yang dapat memenuhi aturan dasar minimum guna confidence 
yaitu dengan melakukan perhitungan confidence dari aturan assosiatif A_B. Adapun nilai confidence dari aturan A _B menghasilkan rumus sebagai berikut:

$$
=\frac{\Sigma \text { Transaksi mengandung } A \& B}{\Sigma \text { Transaksi mengandung A }} * 100 \%
$$

Pada frequent itemset menampilkan itemset yang memiliki kemunculan lebih dari nilai minimum yang ditentukan $(\varnothing)$. Misalkan $\varnothing=2$, maka semua itemsets yang frekuensi kemunculannya sama dengan 2 kali atau lebih dari disebut frequent. Fk merupakan lambing himpunan dari frequent k-itemset.

\section{METODE PENELITIAN}

Dalam penyusunan penelitian dilakukan beberapa tahap untuk mencapai tujuan membuat aturan asosiasi dalam menentukan pola ban hero pada game mobile legends. Cross-Industry Standart Proses for Data Mining (CRISP-DM) menyatakan bahwa putaran waktu proyek data mining yang dikembangkan tahun 1996 terbagi dalam 6 fase (Fachrurozi et al., 2020), sebagai berikut.

1. Fase Pemahaman Bisnis (Business Understanding Phase)

a. Menentukan arah proyek dan kebutuhan secara detail dalam lingkup unit pengolahan data secara keseluruhan.

b. Membuat arah dan batasan menjadi formula dari permasalahan data mining.

c. Menyiapkan perencanaan awal untuk mencapai tujuan yang diinginkan

2. Fase Pemahaman Data (Data Understanding Phase)
a. Pegumpulan data
b. Analisis penyelidikan data untuk mengenali lebih lanjut data dan pencarian pengetahuan awal.
c. Melakukan evaluasi kualitas data
d. Apabila diperlukan pilih sebagian kecil grup data yang mungkin mengundang cara kerja dari permasalahan

3. Fase Pengolahan Data (Data Preparation Phase)

a. Persiapan data awal, kumpulkan data yang akan diterapkan untuk keseluruhan fase berikutnya. Fase ini merupakan pekerjaan berat yang perlu dilaksanakan secara terus menerus.

b. Pilih kasus dan variabel yang akan dianalisis dan yang sesuai analisis yang dilakukan.

c. Pada beberapa variabel jika dibutuhkan perlu dilakukan perubahan.

d. Siapkan data awal sehingga siap untuk perangkat pemodelan.

4. Fase Pemodelan (Modelling Phase)
a. Tentukan dan aplikasikan teknik dari pemodelan yang sesuai
b. Pada permasalahan data mining yang sama perlu diperhatikan bahwa beberapa teknik yang memungkinkan untuk digunakan
c. Jika diperlukan, proses dapat kembali ke fase pengolahan data untuk menjadikan data ke dalam bentuk yang sesuai dengan spesifikasi kebutuhan teknik data mining tertentu

5. Fase Evaluasi
a. Dapatkan kualitas dan efektivitas sebelum diterapkan dengan melakukan evaluasi satu atau lebih model yang diterapkan dalam fase pemodelan
b. Menetapkan apakah model memenuhi tujuan di fase pertama.
c. Menentukan apakah ada permasalahan penting dari penelitian yang tidak tertangani degan baik.
d. Mengambil keputusan yang memiliki kaitan dengan penerapan hasil dari data mining.

6. Fase Penyebaran
a. Menerapkan model yang dihasilkan. Karena terbentuknya suatu model tidak berarti bahwa proyek telah terselesaikan.
b. Turutan sederhana dari penyebaran yaitu pembuatan laporan.
c. Turutan kompleks dari penyebaran yaitu penerapan alur data mining yang dilakukan secara paralel dalam department lainnya.

Proses pada tahap identifikasi masalah berhubungan terhadap pencarian pola ban hero pada game Mobile Legends, dari masalah yang ditemukan dilanjutkan dengan menganalisa kebutuhan. Terdapat 9 atribut untuk kebutuhan penelitian yang merupakan nama nama dari hero mobile legend diantaranya adalah: Chou, Kaja, Harith, Valir, Esmeralda, Khufra, Gusion, Kimmy, dan X Borg.Dalam penelitian ini, media pengumpulan data berupa data primer yaitu dengan mengumpulkan data set dari kuisioner yang sudah disebar oleh peneliti melalui fasilitas Google Form. Terdapat 150 tanggapan dari responden dengan presentase tanggapan 88,7\% adalah player game Mobile Legends dan 11,3\% bukan player Mobile Legends. Setiap responden memberikan penilaian terhadap karakter hero Mobile Legends yang tidak dapat digunaka saat melakukan pertandingan karena dianggap akan menyulitkan bagi tim player. Sehingga menghasilkan berbagai data dan jumlah Hero yang paling sering di Ban. 


\section{HASIL DAN PEMBAHASAN}

Penelitian ini bertujuan untuk mengetahui sejauh mana algoritma Apriori dapat membantu memprediksi pola ban Hero untuk memperoleh kemenangan dalam pertandingan. Maka dilakukan pengujian menggunakan aplikasi Weka dengan tahapan sebagai berikut:

1. Proses Penentuan Data

Dilakukan pengujian dengan aplikasi Weka dimana pada langkah awal dipersiapkan data yang sudah diperoleh dari responden dan diuraikan dengan memanfaatkan aplikasi Microsoft Excel yang berformat extension CSV (Comma Delimited). Berikut merupakan tampilan beberapa data awal yang digunakan.

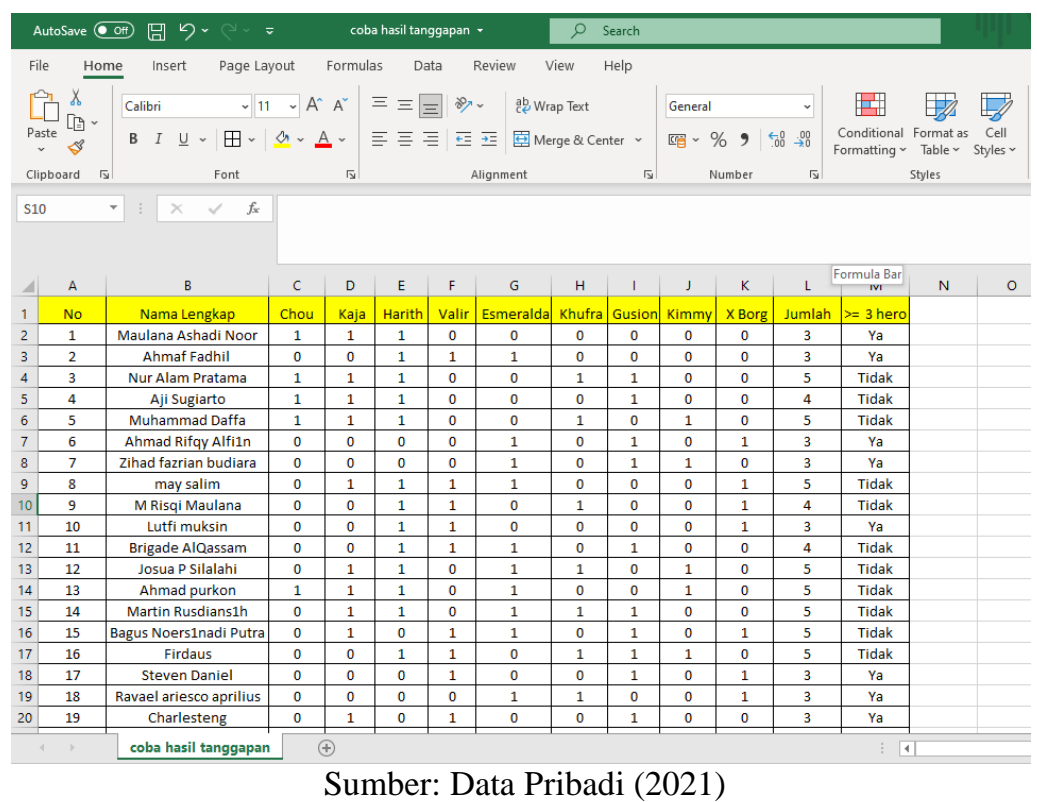

Gambar 1. Persiapan Data Pengujian

2. Pengujian Dengan Weka

Apabila persiapan data telah sesuai, maka aplikasi Weka diaktifkan dan pilih open file. Setelah memasukan data maka diperoleh tampilan hasil pengujian. Berikut tampilan implementasi algoritma Apriori pada Weka.

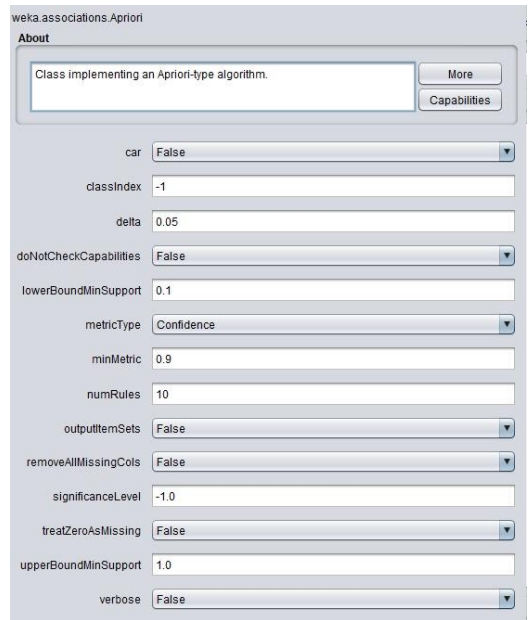

Sumber: Data Pribadi (2021) 
Gambar 2. Implementasi algoritma Apriori

Setelah gambar pemilihan data selesai maka secara otomatis fitur yang disediakan oleh Weka sudah aktif yaitu classify, cluster, Associate dan yang lainnya. Untuk tahapan ini karena yang akan diselesaikan adalah apriori maka pilihan aktif adalah Associate. Setelah proses ini selesai maka pilih Choose dengan memilih apriori dan Tekan Tombol Start maka otomatis muncul analisa dari Apriori seperti gambar berikut ini.

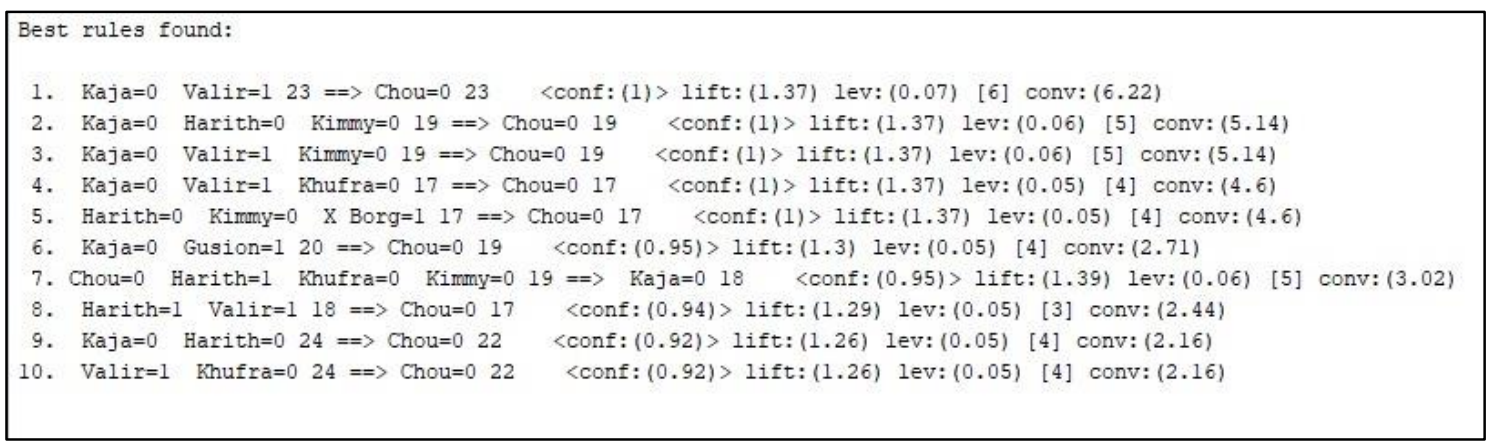

Sumber: Data Pribadi (2021)

Gambar 3. Hasil Analisa Apriori

Rule yang dihasilkan dari data yang tersedia yaitu sebanyak 10 rule dengan tingkatan confindence yang berbeda. Dari pengujian model dengan Weka tersebut maka diperoleh hasil dari data kuesioner sebagai berikut:

1. Kaja=0 Valir=1 $23==>$ Chou=0 23 <conf:(1)> lift:(1.37) lev:(0.07) [6] conv:(6.22)

2. Kaja=0 Harith=0 Kimmy=0 $19==>$ Chou=0 19 <conf:(1)> lift:(1.37) lev:(0.06) [5] conv:(5.14)

3. Kaja=0 Valir=1 Kimmy=0 $19==>$ Chou=0 19 <conf:(1)> lift:(1.37) lev:(0.06) [5] conv:(5.14)

4. Kaja=0 Valir=1 Khufra=0 $17==>$ Chou=0 17 <conf:(1)> lift:(1.37) lev:(0.05) [4] conv:(4.6)

5. Harith=0 Kimmy=0 X Borg=1 17 ==> Chou=0 17 <conf:(1)> lift:(1.37) lev:(0.05) [4] conv:(4.6)

6. Kaja=0 Gusion=1 $20==>$ Chou=0 19 <conf:(0.95)> lift:(1.3) lev:(0.05) [4] conv:(2.71)

7. Chou=0 Harith=1 Khufra=0 Kimmy=0 19 ==> Kaja=0 18 <conf:(0.95)> lift:(1.39) lev:(0.06) [5] conv:(3.02)

8. Harith=1 Valir=1 $18==>$ Chou=0 17 <conf:(0.94)> lift:(1.29) lev:(0.05) [3] conv:(2.44)

9. Kaja=0 Harith=0 $24==>$ Chou=0 22 <conf:(0.92)> lift:(1.26) lev:(0.05) [4] conv:(2.16)

10. Valir=1 Khufra=0 24 ==> Chou=0 22 <conf:(0.92)> lift:(1.26) lev:(0.05) [4] conv:(2.16)

Berikut merupakan cara membaca hasil data diatas:

1. Apabila player tidak ban KAJA tetapi ban VALIR maka player tidak ban CHOU dengan nilai confidence $100 \%$

2. Apabila player tidak ban KAJA, HARITH dan KIMMY maka player tidak ban CHOU dengan nilai confidence $100 \%$

3. Apabila player tidak ban KAJA dan KIMMY tetapi ban VALIR maka player tidak ban CHOU dengan nilai confidence $100 \%$

4. Apabila player tidak ban KAJA dan KHUFRA tetapi ban VALIR maka player tidak ban CHOU dengan nilai confidence $100 \%$

5. Apabila player tidak ban HARITH dan KIMMY tetapi ban X BORG maka player tidak ban CHOU dengan nilai confidence $100 \%$

6. Apabila player tidak ban KAJA tetapi ban GUSION maka player tidak ban CHOU dengan nilai confidence $100 \%$

7. Apabila player tidak ban CHO, KHUFRA, dan KIMMY tetapi ban HARITH maka player tidak ban KAJA dengan nilai confidence $100 \%$

8. Apabila player ban HARITH dan VALIR maka player tidak ban CHOU dengan nilai confidence $100 \%$

9. Apabila player tidak ban KAJA dan HARITH maka player tidak ban CHOU dengan nilai confidence $100 \%$

10. Apabila player ban VALIR tetapi tidak ban KHUFRA maka player tidak ban CHOU dengan nilai confidence $100 \%$ 


\section{KESIMPULAN}

Penelitian ini menghasilkan data yang dimana data tersebut merupakan aturan asosiasi dari kumpulan data responden pada kuesioner untuk mengetahui pola ban Hero pada Mobile Legends. Dari aturan asosiasi tersebut dapat diperoleh pola player dalam melakukan ban Chou lebih jarang dilakukan terbukti dari hasil perhitungan menggunakan Algoritma Apriori, bahwa hero dengan nama Chou yang paling sering muncul dengan nilai 0 atau tidak di ban. Sehingga dengan diketahuinya pola ban Hero tersebut, maka player maupun pengembang games Mobile Legends dapat memprediksi kemenangan tim yang menggunakan Hero tersebut, dan dapat memperhitungkan kemungkinan penggunaan Hero lainnya. Diketahui juga penerapan Apriori menghasilkan beberapa rule yang dapat digunakan dalam menggali informasi yang terkandung didalam tumpukan data ataupun big data. Dengan pengujian algoritma menggunakan aplikasi Weka maka proses semakin efektif dan menghasilkan suatu rule dengan waktu yang singkat.

\section{REFERENSI}

Damariva, Z., Santiya, J. W., Hutomo, R., \& Ardiko, D. (2018). Identification of Forms of Capital in Multiplayer Online Battle Arena (MOBA) Video Games: Study of Mobile Legends Gamers in Indonesia. Indonesia International Graduate Conference on Communication (IndoIGCC) Proceeding, 2, 336-349.

Fachrurozi, A., Junaedi, M., Putra, J. L., \& Gata, W. (2020). Algorithm Implementation Of Interest Buy Apriori Data On Consumer Retail Sales In Industry. Journal of Informatics and Telecommunication Engineering, 4(1), 48-56. https://doi.org/10.31289/jite.v4i1.3775

GIBRAN, R. (2016). Analisis Aturan Asosiasi Menggunakan Algoritma Apriori Untuk Menentukan Inventori Apotek. Skripsi, Fakultas Ilmu Komputer, 5.

Gunadi, G., \& Sensuse, D. I. (2016). Penerapan metode data mining market basket analysis terhadap data penjualan produk buku dengan menggunakan algoritma apriori dan frequent pattern growth (fp-growth): studi kasus percetakan PT. Gramedia. Telematika MKOM, 4(1), 118-132.

Leonardo, V., Santoso, L. W., Tjondrowiguno, A. N., Studi, P., Informatika, T., Industri, F. T., Petra, U. K., \& Siwalankerto, J. (2018). Sistem Rekomendasi Item Pada Game Dota 2 dengan Multilayer Perceptron Neural Network.

Mustofa, Selawati, A., Asteroid, kurani mega, \& Ridha, meirina suci. (2018). IMPLEMENTASI ALGORITMA APRIORI UNTUK ANALISA PEMILIHAN TIPE KARAKTER PADA PERMAINAN MOBILE LEGEND. AKRAB JUARA, 3(1), 1-7.

Pascarella, L., Palomba, F., Di Penta, M., \& Bacchelli, A. (2018). How is video game development different from software development in open source? Proceedings - International Conference on Software Engineering, 392-402. https://doi.org/10.1145/3196398.3196418

Putra, J. L., Raharjo, M., Sandi, T. A. A., Ridwan, R., \& Prasetyo, R. (2019). Implementasi Algoritma Apriori Terhadap Data Penjualan Pada Perusahaan Retail. Jurnal Pilar Nusa Mandiri, 15(1), 85-90. https://doi.org/10.33480/pilar.v15i1.113

Summerville, A., Cook, M., \& Steenhuisen, B. (2016). Draft-Analysis of the ancients: Predicting draft picks in DotA 2 using machine learning. AAAI Workshop - Technical Report, WS-16-21-(Godec), 100-106.

Syahputri, N. (2020). Penerapan Data Mining Asosiasi pada Pola Transaksi dengan Metode Apriori. J-SAKTI (Jurnal Sains Komputer Dan Informatika), 4(September), 728-736. 